\title{
Effect of thermal radiation on boundary layer flow and heat transfer of dusty fluid over an unsteady stretching sheet
}

\author{
S. Manjunatha, B. J. Gireesha ${ }^{1}$ and C. S. Bagewadi \\ Department of Studies and Research in Mathematics, Kuvempu University, Shankaraghatta-577 451, Shimoga, Karnataka, INDIA. \\ ${ }^{1}$ Corresponding Author: e-mail: bjgireesu@rediffmail.com Tel: 091+9741148002
}

\begin{abstract}
The aim of this paper is to study the boundary layer flow and heat transfer analysis of an unsteady viscous dusty fluid over a porous stretching surface. Momentum Boundary layer equation considers the effect of transverse magnetic field whereas thermal Boundary layer equation considers the effect of thermal radiation. The governing partial Differential equations are reduced to coupled non-linear ordinary differential equations using similarity transformation. Numerical solutions of these equations are obtained with the help of RKF-45 method. The solution is found to be dependent on different governing parameters. Some important findings reported in this work reveal that the effect of radiation has significant impact in controlling the rate of heat transfer in the boundary layer region.
\end{abstract}

Keywords: Unsteady flow and heat transfer; Boundary layer flow; Stretching porous Surface; Dusty fluid; Thermal radiation; Numerical solution.

AMS Subject Classification (2010): 76T15 and 80A20

DOI: http://dx.doi.org/10.4314/ijest.v4i4.4

\section{Introduction}

The study of boundary layer flow and heat transfer analysis of dusty fluid due to a continuously moving stretching surface through an ambient liquid is one of thrust areas of current research. This finds its applications over a broad spectrum of science and engineering disciplines, especially in the field of chemical engineering. Many chemical engineering processes like metallurgical process, polymer extrusion process involving cooling of a molten liquid being stretched into a cooling system. The fluid mechanical properties desired for an outcome of such a process would mainly depend on two aspects, one is the cooling liquid used and the other is the rate of stretching. Rate of stretching is very important as rapid stretching results in sudden solidification, thereby destroying the properties expected for the outcome. The problem mentioned here frequently arises in many practical situations such as polymer extrusion process. It is also encountered with the other process like drawing, annealing and tinning of copper wires, continuous stretching, rolling and manufacturing of plastic films and artificial fibers, heat treated materials traveling on conveyer belts, glass blowing, crystal growing, paper production and so on.

Sakiadis (1961) initiated the study of the boundary layer flow over a stretched surface moving with a constant velocity and formulated a boundary-layer equation for two-dimensional and axisymmetric flows. Tsou et al. (1967) analyzed the effect of heat transfer in the boundary layer on a continuous moving surface with a constant velocity and experimentally confirmed the numerical results of Sakiadis (1961). Carragher et.al. (1982) investigated the heat transfer in the flow over a stretching surface in the case when the temperature difference between the surface and the ambient fluid is proportional to a power of distance from the fixed point. Vajravelu et.al (1992) have discussed hydromagnetic flow of a dusty fluid over a stretching sheet. Sharidan et.al (2006) haves studied similarity solutions for the unsteady boundary layer flow and heat transfer due to a stretching sheet. Subhas Abel et.al (2007) have studied the flow and heat transfer in a viscoelastic boundary layer flow over a stretching sheet with prescribed surface temperature (PST) case and prescribed heat flux (PHF) case. Elbashbeshy et.al (2010) have studied effect of 
thermal radiation and magnetic field on unsteady mixed convection flow and heat transfer over a porous stretching surface. Subhas Abel et.al (2008) discussed heat transfer in MHD visco-elastic fluid flow over a stretching sheet with variable thermal conductivity, non-uniform heat source and radiation. Grubka et.al (1985) have studied the temperature field in the flow over a stretching surface subjected to a uniform heat flux. Andersson et al. (2000) presented a new similarity solution for the temperature fields, which transforms the time-dependent thermal energy equation to an ordinary differential equation. Ali et.al (2011) have studied unsteady flow and heat transfer past an axisymmetric permeable shrinking sheet with radiation effect. Sharma et.al (2009) obtained the results for the effects of variable thermal conductivity and heat source/sink on MHD flow near a stagnation point on a linearly stretching sheet. Subhas Abel (2009) et.al have analyzed the MHD flow and heat transfer to a laminar liquid film from a horizontal stretching surface with the aid of similarity transformation. The transformation enables to reduce the unsteady boundary layer equations to a system of non-linear ordinary differential equations. Numerical solution of resulting nonlinear differential equations is found by using efficient shooting technique. Abdul Aziz (2009) obtained the numerical solution for laminar thermal boundary over a flat plate with a convective surface boundary condition using the symbolic algebra software Maple.

Mukhopadhyay (2009) has studied the effect of thermal radiation on unsteady mixed convection flow and heat transfer over a porous stretching surface in porous medium. Hayat (2010) et.al. have discussed the influence of radiation on magnetohydrodynamic (MHD) and mass transfer flow over a porous stretching sheet. Attention has been particularly focused to the unsteadiness. Hayat (2011) et al. have studied the magnetohydrodynamic (MHD) flow and heat transfer characteristics for the boundary layer flow over a permeable stretching sheet in the presence of velocity and thermal slip conditions. Anura Ishak (2010) has studied the thermal boundary layer flow over a stretching sheet in a micropolar fluid with radiation effect. The governing similarity equations contain Prandtl number, Eckret number, number density and unsteadiness parameter. Although a similarity solution is accomplished by these authors, some physically unrealistic phenomena are encountered for specific values of the unsteadiness.

In view of the above discussion, the present paper concentrated on investigation of two-dimensional unsteady state dusty viscous and incompressible thermal boundary layer flow over a stretching sheet with radiation effect. In addition, both the variable wall temperature (VWT) and variable heat flux (VHF) conditions have been considered. The governing equations are solved numerically using RKF-45 method with the help of symbolic algebra software Maple.

\section{Mathematical Formulation}

Consider the two-dimensional unsteady boundary layer flow of an electrically conducting viscous and incompressible dusty fluid past a semi-infinite stretching sheet in the region $y>0$. In the present study the flow is considered to be generated by stretching of an elastic boundary sheet from a slit with the application of two equal and opposite forces in such way that velocity of boundary sheet is linear order of the flow directional coordinate $X$. A uniform magnetic field $\hat{B}_{0}$ is also imposed along the $y$ axis.

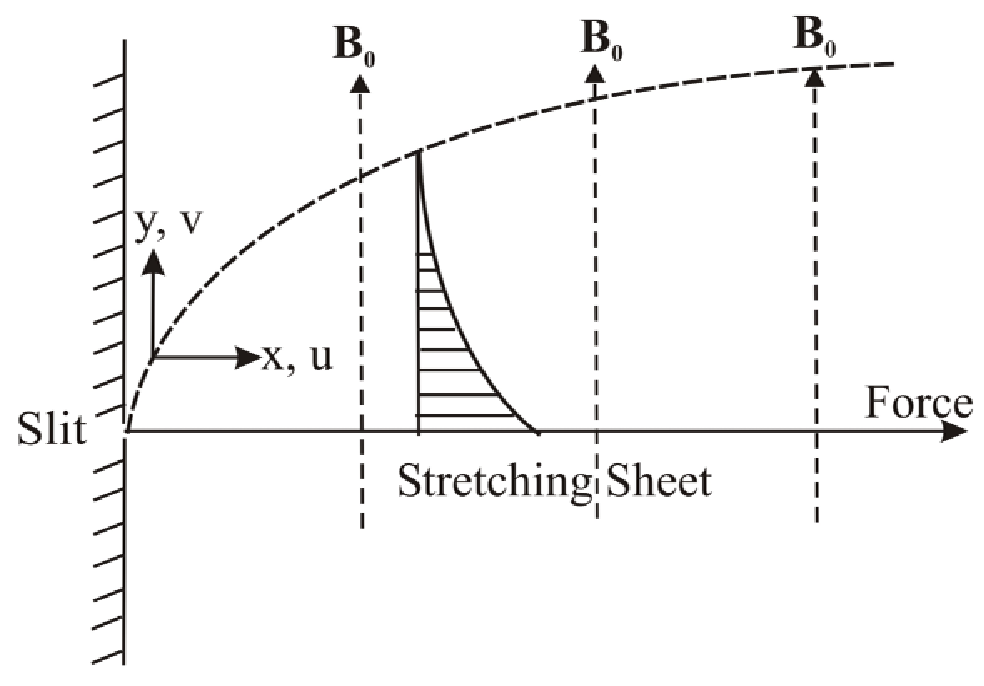

Figure 1: Schematic diagram of the flow geometry.

The unsteady two-dimensional boundary layer equations of dusty fluid in usual notation are:

$$
\frac{\partial u}{\partial x}+\frac{\partial v}{\partial y}=0
$$




$$
\begin{aligned}
& \frac{\partial u}{\partial t}+u \frac{\partial u}{\partial x}+v \frac{\partial u}{\partial y}=\frac{\mu}{\rho} \frac{\partial^{2} u}{\partial y^{2}}+\frac{K N}{\rho}\left(u_{p}-u\right)-\frac{\sigma \hat{B}_{0}^{2}}{\rho}, \\
& \frac{\partial u_{p}}{\partial t}+u_{p} \frac{\partial u_{p}}{\partial x}+v_{p} \frac{\partial u_{p}}{\partial y}=\frac{K}{m}\left(u-u_{p}\right), \\
& \frac{\partial v_{p}}{\partial t}+u_{p} \frac{\partial v_{p}}{\partial x}+v_{p} \frac{\partial v_{p}}{\partial y}=\frac{K}{m}\left(v-v_{p}\right), \\
& \frac{\partial}{\partial x}\left(\rho_{p} u_{p}\right)+\frac{\partial}{\partial y}\left(\rho_{p} v_{p}\right)=0
\end{aligned}
$$

In deriving these equations, the Stokesian drag force is considered for the interaction between the fluid and particle phase and the induced magnetic field is neglected. It is also assumed that the external electric field is zero and the electric field due to polarization of charges is negligible.

The boundary conditions applicable to the above problem are:

$$
\begin{aligned}
& u=U_{w}(x, t), \quad v=V_{w}(x, t) \quad \text { at } \quad y=0, \\
& u \rightarrow 0, u_{p} \rightarrow 0, v_{p} \rightarrow v, \rho_{p} \rightarrow k \rho \quad \text { as } \quad y \rightarrow \infty,
\end{aligned}
$$

Equations (2.1) to (2.5) subjected to boundary condition (2.6), admits self-similar solution in terms of the similarity function $f$ and the similarity variable $\eta$ is defined as

$$
\begin{aligned}
& u=\frac{c x}{1-\alpha t} f^{\prime}(\eta), \quad v=-\sqrt{\frac{c v}{1-\alpha t}} f(\eta), \quad \eta=\sqrt{\frac{c}{v(1-\alpha t)}} y, \\
& u_{p}=\frac{c x}{1-\alpha t} F(\eta), \quad v_{p}=\sqrt{\frac{c v}{1-\alpha t}} G(\eta), \quad \rho_{r}=H(\eta), \\
& \hat{B}^{2}{ }_{0}=B_{0}{ }^{2}(1-\alpha t)^{-1 / 2}
\end{aligned}
$$

where a prime denotes the differentiation with respect to $\eta$. Substituting the equations (2.7) into equations (2.1) to (2.5) one can get

$$
\begin{aligned}
& f^{\prime \prime \prime}(\eta)+f(\eta) f^{\prime \prime}(\eta)-\left[f^{\prime}(\eta)\right]^{2}-A\left[f^{\prime}(\eta)+\frac{\eta}{2} f^{\prime \prime}(\eta)\right] \\
& +l \beta H(\eta)\left[F(\eta)-f^{\prime}(\eta)\right]-M f^{\prime}(\eta)=0, \\
& A\left[F(\eta)+\frac{\eta}{2} F^{\prime}(\eta)\right]+G(\eta) F^{\prime}(\eta)+[F(\eta)]^{2}+\beta\left[F(\eta)-f^{\prime}(\eta)\right]=0, \\
& \frac{A}{2}\left[G(\eta)+\frac{\eta}{2} G^{\prime}(\eta)\right]+G(\eta) G^{\prime}(\eta)+\beta[f(\eta)+G(\eta)]=0, \\
& H(\eta) F(\eta)+H(\eta) G^{\prime}(\eta)+G(\eta) H^{\prime}(\eta)=0,
\end{aligned}
$$


The corresponding boundary conditions are transformed to:

$$
\begin{aligned}
& f^{\prime}(\eta)=1, \quad f(\eta)=R \quad \text { at } \quad \eta=0 \\
& f^{\prime}(\eta)=0, F(\eta)=0, G(\eta)=-f(\eta), H(\eta)=E \quad \text { as } \quad \eta \rightarrow \infty .
\end{aligned}
$$

If $A=0$, the analytical and numerical solution of equations (2.1) to (2.5) was given by Vajravelu and Nayfeh [4].

\section{Heat transfer analysis}

The unsteady boundary layer heat transport equation in the presence of thermal radiation for two dimensional flows is given by

$$
\begin{aligned}
& \rho c_{p}\left(\frac{\partial T}{\partial t}+u \frac{\partial T}{\partial x}+v \frac{\partial T}{\partial y}\right)=k^{*} \frac{\partial^{2} T}{\partial y^{2}}+\frac{N c_{p}}{\tau_{T}}\left(T_{p}-T\right)+\frac{N}{\tau v}\left(u_{p}-u\right)^{2}-\frac{\partial q_{r}}{\partial y}+\mu\left(\frac{\partial u}{\partial y}\right)^{2}, \\
& N c_{m}\left(\frac{\partial T_{p}}{\partial t}+u_{p} \frac{\partial T_{p}}{\partial x}+v_{p} \frac{\partial T_{p}}{\partial y}\right)=-\frac{N c_{p}}{\tau_{T}}\left(T_{p}-T\right) .
\end{aligned}
$$

Following Rosseland approximation (1972) the radiative heat flux $q_{r}$ is modeled as

$$
q_{r}=-\frac{4 \sigma^{*}}{3 k_{1}} \frac{\partial T^{4}}{\partial y}
$$

Assuming that the differences in the temperature within the flow are such that $T^{4}$ can be expressed as linear combination of the temperature, one can expand $T^{4}$ in a Taylor's series about $T_{\infty}$ as follows

$$
T^{4}=T_{\infty}^{4}+4 T_{\infty}^{3}\left(T-T_{\infty}\right)+6 T_{\infty}^{2}\left(T-T_{\infty}\right)^{2}+\cdots
$$

By neglecting higher order terms beyond the first degree in $\left(T-T_{\infty}\right)$ we get

$$
T^{4}=-3 T_{\infty}^{4}+4 T_{\infty}^{3} T \text {. }
$$

Substituting equation (3.5) in equation (3.3) we obtain

$$
\frac{\partial q_{r}}{\partial y}=-\frac{16 T_{\infty}^{3} \sigma^{*}}{3 k_{1}} \frac{\partial^{2} T}{\partial y^{2}}
$$

The solution of equations (3.1) and (3.2) depends on the nature of the prescribed boundary condition. The two types of heating processes are discussed below.

\section{CASE-1: Variable wall temperature (VWT)}

For this heating process, the variable wall temperature is assumed to be a quadratic function of $X$ and is given by

$$
\begin{aligned}
& T=T_{w}=T_{\infty}+T_{0}\left(\frac{c x^{2}}{v(1-\alpha t)^{2}}\right) \text { at } y=0 . \\
& T \rightarrow T_{\infty}, \quad T_{p} \rightarrow T_{\infty} \quad \text { as } y \rightarrow \infty,
\end{aligned}
$$

In order to obtain similarity solution for temperatures $\theta(\eta)$ and $\theta_{p}(\eta)$, define dimensionless variables as follows:

$$
\theta(\eta)=\frac{T-T_{\infty}}{T_{w}-T_{\infty}}, \quad \theta_{p}(\eta)=\frac{T_{p}-T_{\infty}}{T_{w}-T_{\infty}},
$$


where $T-T_{\infty}=T_{0}\left(\frac{c x^{2}}{v(1-\alpha t)^{2}}\right) \theta(\eta)$.

Using Equations (3.6), (3.7) and (3.8) in the Equations (3.1) and (3.2), we get

$$
\begin{aligned}
& (1+N r) \theta^{\prime \prime}(\eta)+\operatorname{Pr}\left[f(\eta) \theta^{\prime}(\eta)-2 f^{\prime}(\eta) \theta(\eta)\right]-\frac{A}{2} \operatorname{Pr}\left[4 \theta(\eta)+\eta \theta^{\prime}(\eta)\right] \\
& +\frac{N}{\rho} \operatorname{Pr} E c \beta\left[F(\eta)-f^{\prime}(\eta)\right]^{2}+\frac{N}{\rho} \operatorname{Pr} a_{1}\left[\theta_{p}(\eta)-\theta(\eta)\right]+\operatorname{Pr} E c\left(f^{\prime}(\eta)\right)^{2}=0, \\
& G(\eta) \theta_{p}^{\prime}(\eta)+2 F(\eta) \theta_{p}(\eta)+\frac{A}{2}\left[4 \theta_{p}(\eta)+\eta \theta_{p}^{\prime}(\eta)\right]+a_{1} \gamma\left[\theta_{p}(\eta)-\theta(\eta)\right]=0,
\end{aligned}
$$

Using the Equations (3.7) and (3.8) the corresponding boundary conditions for $\theta(\eta)$ and $\theta_{p}(\eta)$, reduces to following form

$$
\begin{aligned}
& \theta(\eta)=1 \quad \text { at } \quad \eta=0 \\
& \theta(\eta) \rightarrow 0, \quad \theta_{p}(\eta) \rightarrow 0 \quad \text { as } \eta \rightarrow \infty
\end{aligned}
$$

\section{CASE-2: Variable heat flux (VHF-Case)}

In this heating process we employ the following variable heat flux boundary conditions.

$$
\begin{aligned}
& \frac{\partial T}{\partial y}=-\frac{q_{w}(x, t)}{k^{*}} \text { at } y=0, \\
& T \rightarrow T_{\infty}, T_{p} \rightarrow T_{\infty} \quad \text { as } y \rightarrow \infty,
\end{aligned}
$$

Where $q_{w}(x, t)=q_{w_{0}} x^{2}\left(\frac{c}{v}\right)^{3 / 2}(1-\alpha t)^{-5 / 2}$.

In order to obtain similarity solution for temperature, define dimensionless temperature variables in VHF case as same in equation (3.8), where $T_{w}-T_{\infty}=\frac{q_{w_{0}}}{k^{*}}\left[\frac{c x^{2}}{v(1-\alpha t)^{2}}\right] \theta(\eta)$.

Using dimensionless variable (3.8), the temperature equations (3.1) and (3.2) takes the form

$$
\begin{aligned}
& (1+N r) \theta^{\prime \prime}(\eta)+\operatorname{Pr}\left[f(\eta) \theta^{\prime}(\eta)-2 f^{\prime}(\eta) \theta(\eta)\right]-\frac{A}{2} \operatorname{Pr}\left[4 \theta(\eta)+\eta \theta^{\prime}(\eta)\right] \\
& +\frac{N}{\rho} \operatorname{Pr} E c \beta\left[F(\eta)-f^{\prime}(\eta)\right]^{2}+\frac{N}{\rho} \operatorname{Pr} a_{1}\left[\theta_{p}(\eta)-\theta(\eta)\right]+\operatorname{Pr} E c\left(f^{\prime}(\eta)\right)^{2}=0, \\
& G(\eta) \theta_{p}^{\prime}(\eta)+2 F(\eta) \theta_{p}(\eta)+\frac{A}{2}\left[4 \theta_{p}(\eta)+\eta \theta_{p}^{\prime}(\eta)\right]+a_{1} \gamma\left[\theta_{p}(\eta)-\theta(\eta)\right]=0,
\end{aligned}
$$

The corresponding boundary conditions becomes

$$
\begin{aligned}
& \theta^{\prime}(\eta)=-1 \quad \text { at } \quad \eta=0, \\
& \theta(\eta) \rightarrow 0, \quad \theta_{p}(\eta) \rightarrow 0 \quad \text { as } \eta \rightarrow \infty .
\end{aligned}
$$


The physical quantities of interest are the skin friction coefficient $C_{f}$ and the local Nusselt number $N u_{x}$, which are defined as

$$
c_{f}=\frac{\tau_{w}}{\rho U_{w}{ }^{2}}, \quad N u_{x}=\frac{x q_{w}}{k\left(T_{w}-T_{\infty}\right)},
$$

where the skin friction $\tau_{w}$ and the heat transfer from the sheet $q_{w}$ are given by

$$
\tau_{w}=\mu\left(\frac{\partial u}{\partial y}\right)_{y=0}, \quad q_{w}=k\left(\frac{\partial T}{\partial y}\right)_{y=0},
$$

Using the non-dimensional variables, we obtain

$$
c_{f} \operatorname{Re}_{x}^{1 / 2}=f^{\prime \prime}(0), \quad \quad N u_{x} / \operatorname{Re}_{x}^{1 / 2}=\theta^{\prime}(0)(V W T), \quad N u_{x} / \operatorname{Re}_{x}^{1 / 2}=-1 / \theta(0)(V H F) .
$$

\section{Numerical solution}

The equations (2.8) and (2.11) together with the boundary condition (2.12) form highly non-linear ordinary differential equations. In order to solve these non-linear equations numerically, we have adopted symbolic software Maple (2009) and it is very efficient in using the well known Runge Kutta Fehlberg fourth-fifth order method. In accordance with the boundary layer analysis, the boundary condition (2.12) at $\eta=\infty$ were replaced by $\eta=5$. The coupled boundary value problem equations (2.8) to (2.11) and either equations (3.9) and (3.10) or (3.13) and (3.14) are solved by RKF-45 method. The accuracy of this numerical method was validated by direct comparison with the numerical results reported by Vajravelu and Nayfeh (1992) and Grubka and Bobba (1985). Table 1 represents Comparison of numerical solutions of $f(\eta), f^{\prime}(\eta), f^{\prime \prime \prime}(\eta)$ with $A=0, M=3, R=2, \beta=0$, and Table 2 represents results of the comparison for $-\theta^{\prime}(0)$ with $(A=N r=E c=0)$. It can be seen from these tables that there is a very good agreement achieved between the results.

Table-1: Comparison of numerical solutions of $f(\eta), f^{\prime}(\eta), f^{\prime \prime \prime}(\eta)$ with $A=0, M=3, R=2, \beta=0$.

\begin{tabular}{|c|ccc|ccc|}
\hline & \multicolumn{3}{|c|}{ Vajravelu And Nayfeh (1992) } & \multicolumn{3}{c|}{ Present Result } \\
\hline$\eta$ & $f(\eta)$ & $f^{\prime}(\eta)$ & $f^{\prime \prime}(\eta)$ & $f(\eta)$ & $f^{\prime}(\eta)$ & $f^{\prime \prime}(\eta)$ \\
\hline 0.00000 & 2.000000 & 1.000000 & -3.236068 & 2.000000 & 1.000000 & -3.236068 \\
& & & & & \\
0.408163 & 2.226537 & 0.266910 & -0.863739 & 2.226537 & 0.266910 & -0.863739 \\
0.816327 & 2.287002 & 0.071241 & -0.230540 & 2.287002 & 0.071241 & -0.230540 \\
1.224490 & 2.303141 & 0.019015 & -0.061534 & 2.303141 & 0.019015 & -0.061534 \\
1.632653 & 2.307448 & 0.005075 & -0.016424 & 2.307449 & 0.005075 & -0.016424 \\
2.040816 & 2.308598 & 0.001355 & -0.043840 & 2.308598 & 0.001355 & -0.004384 \\
2.448980 & 2.308905 & 0.000362 & -0.001170 & 2.308905 & 0.000362 & -0.001170 \\
2.857143 & 2.308987 & 0.000096 & -0.000312 & 2.308987 & 0.000097 & -0.000312 \\
3.265306 & 2.309009 & 0.000026 & -0.000083 & 2.309009 & 0.000026 & -0.000083 \\
3.673469 & 2.309015 & 0.000007 & -0.000022 & 2.309015 & 0.000007 & -0.000022 \\
4.081633 & 2.309016 & 0.000002 & -0.000006 & 2.309016 & 0.000002 & -0.000006 \\
4.489796 & 2.309017 & 0.000000 & -0.000002 & 2.309017 & 0.000000 & -0.000002 \\
\hline 4.897959 & 2.309017 & 0.000000 & -0.000001 & 2.309017 & 0.000000 & 0.000000 \\
5.000000 & 2.309017 & 0.000000 & 0.000000 & 2.3090167 & 0.000000 & 0.000000 \\
\hline
\end{tabular}


Table-2: Comparison of wall temperature gradient $-\theta^{\prime}(0)$ for several values of $\operatorname{Pr}$ with $(\alpha=\beta=N=A=N r=E c=0)$.

\begin{tabular}{|c|c|c|c|}
\hline$P r$ & $\begin{array}{c}\text { Grubka and Bobba } \\
(1985)\end{array}$ & $\begin{array}{c}\text { M. Subhas Abel and Mahesha } \\
(2008)\end{array}$ & Present Study $-\theta^{\prime}(0)$ \\
\hline 0.72 & 1.0885 & 1.0885 & 1.0885 \\
1.0 & 1.3333 & 1.3333 & 1.3333 \\
10.0 & 4.7969 & 4.7968 & 4.7968 \\
\hline
\end{tabular}

\section{Results and discussion}

An unsteady boundary layer flow and heat transfer of an incompressible electrically conducting dusty fluid over a stretching sheet with radiation effect is examined. The boundary layer equations of momentum and heat transfer are solved numerically. The temperature profiles of both fluid and dust phase for VWT and VHF case are depicted graphically. The computation through employed numerical scheme has been carried out for various values of the parameters such as unsteadiness parameter $A$, magnetic parameter $M$, suction parameter $R$, fluid particle interaction parameter $\beta$, Prandtl number $\operatorname{Pr}$, number density $N$, Eckert number $E c$ and Thermal radiation parameter $N r$.

Figure 2(a) represents horizontal velocity profile of both fluid and dust particles for various value of $A$ when $\operatorname{Pr}=0.72, R=2, M=0.1, N=0.2, N r=1$ and $\beta=0.1$. One can observe from the figure 2(a) that the velocity decreases with the increase of the unsteady parameter $A$. It is interesting to note that the thickness of boundary deceases with increasing values of $A$. This is due to the fluid flow caused solely by the stretching sheet. From the figure 2(b), one can observe that the velocity decreases with the increase of magnetic parameter $M$. As $M$ increases, the Lorentz force, which opposes the flow, also increases and leads to enhanced deceleration of the flow.

Figures 3(a) and 3(b) is a graphical representation of the temperature distribution for VWT and VHF case, for different values of unsteady parameter $A$ versus $\eta$. It is observed that the temperature of fluid and dust particle is decreases with the increase of unsteady parameter $A$. Temperature at a point of surface decreases significantly with the increase of $A$ i.e. rate of heat transfer increases with increasing unsteady parameter $A$. Physically, it means that the temperature gradient at the surface increases as $A$ increases, which imply the increase of heat transfer rate $-\theta^{\prime}(\eta)$ at the surface.

Figures 4(a) and 4(b) depict temperature profiles $\theta(\eta)$ and $\theta_{p}(\eta)$ versus $\eta$, for different values of $\operatorname{Pr}$. We infer from these figures that temperature of fluid and dust particles decrease with the increase in $\operatorname{Pr}$, this is because of the increase in Prandtl number Pr indicates the increase of the fluid heat capacity or the decrease of the thermal diffusivity hence causes a diminution of the influence of the thermal expansion to the flow. Which implies momentum boundary layer is thicker than the thermal boundary layer. The temperature in both VWT and VHF cases asymptotically approaches to zero in the free stream region

Figures 5(a) and 5(b) indicate the temperature profile $\theta(\eta)$ and $\theta_{p}(\eta)$ versus $\eta$, for VWT and VHF cases respectively. Here the effect of increasing values of $E c$ is to enhance the temperature of fluid and dust particles at any point which is true for both the cases VWT and VHF. This is due to fact that the heat energy is stored in the considered liquid due to frictional heating.

Figures 6(a) and 6(b) are the graphs for temperature profiles $\theta(\eta)$ and $\theta_{p}(\eta)$ versus $\eta$, for different values of Number density $N$ for VWT and VHF cases respectively. From the figures it is evident that the temperature of fluid and dust particles decreases with the increase of $N$.

Figures 7(a) and 7(b) represent the temperature profiles $\theta(\eta)$ and $\theta_{p}(\eta)$ for various values of thermal radiation parameter $\mathrm{Nr}$ for both the cases VWT and VHF respectively. The effect of radiation intensifies the heat transfer. Thus the radiation should be at its minimum in order to facilitate the cooling process. This agrees with the physical fact that the thermal boundary layer thickness increases with increasing values $\mathrm{Nr}$. 

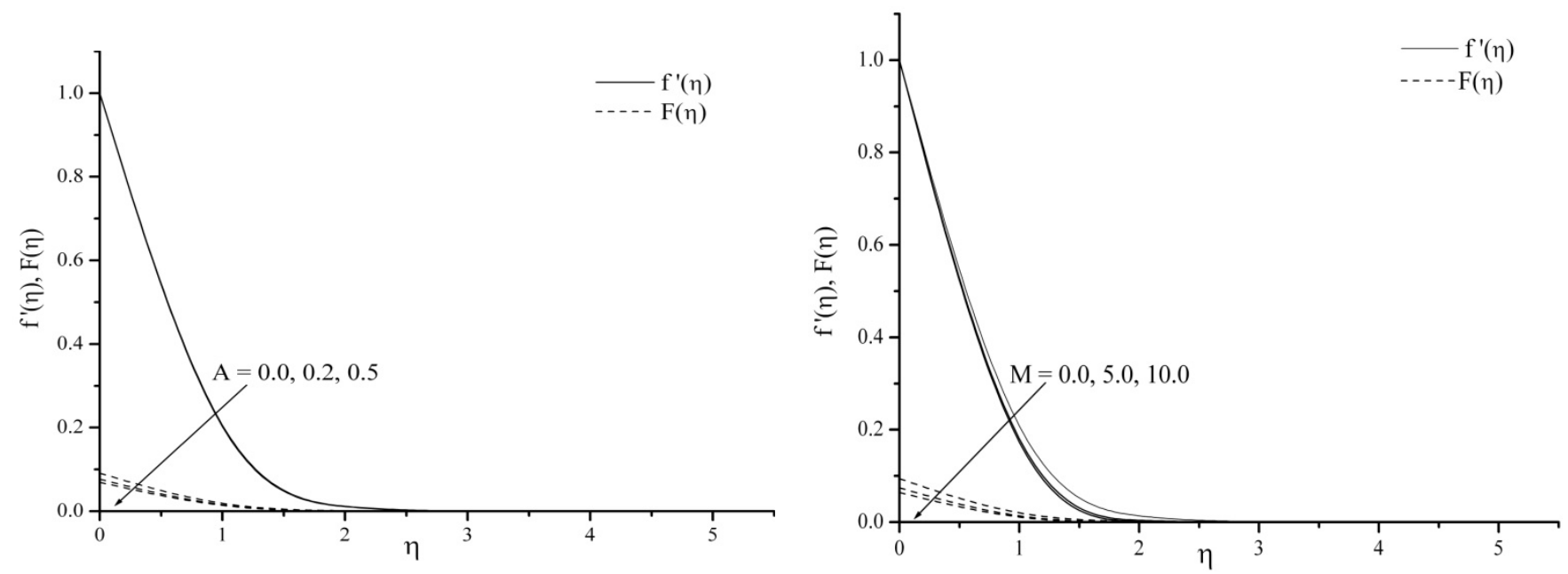

Figures 2(a) \& 2(b): Velocity profiles for the effect of unsteadiness parameter $(A)$ and Magnetic parameter $(M)$ respectively.
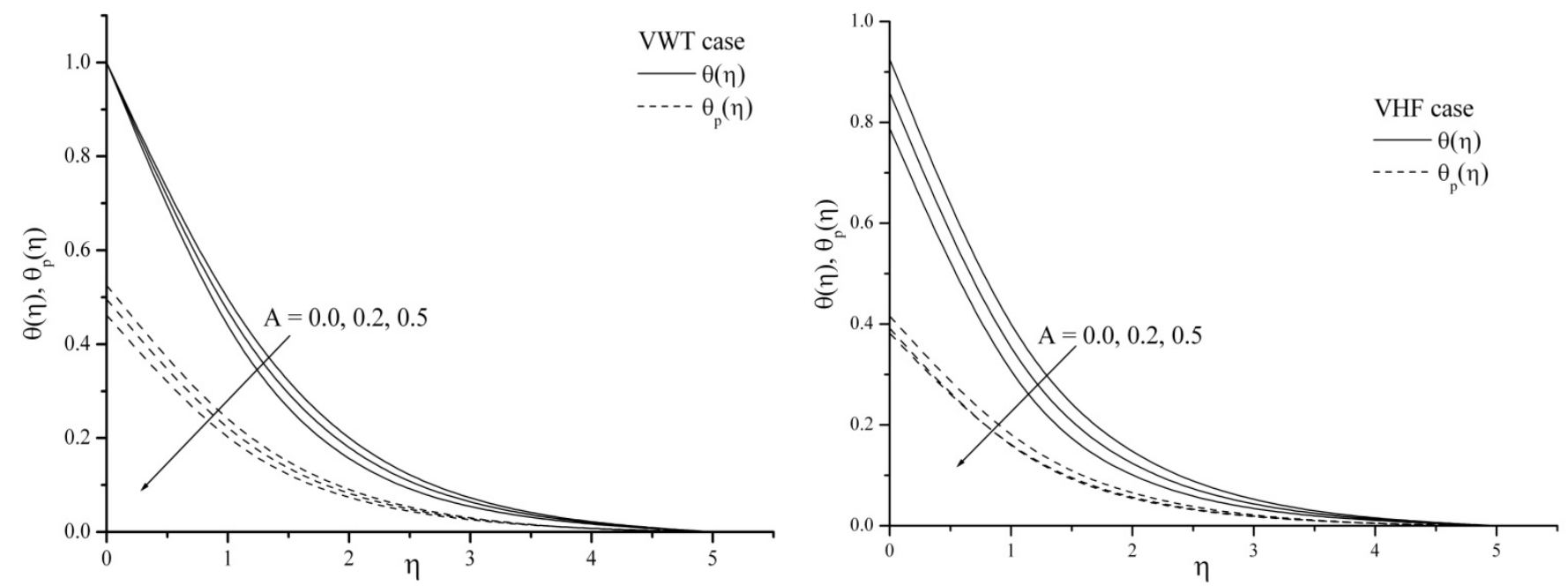

Figure 3(a) \& 3(b): Effect of unsteady parameter $(A)$ on temperature distribution for fluid and dust phase.
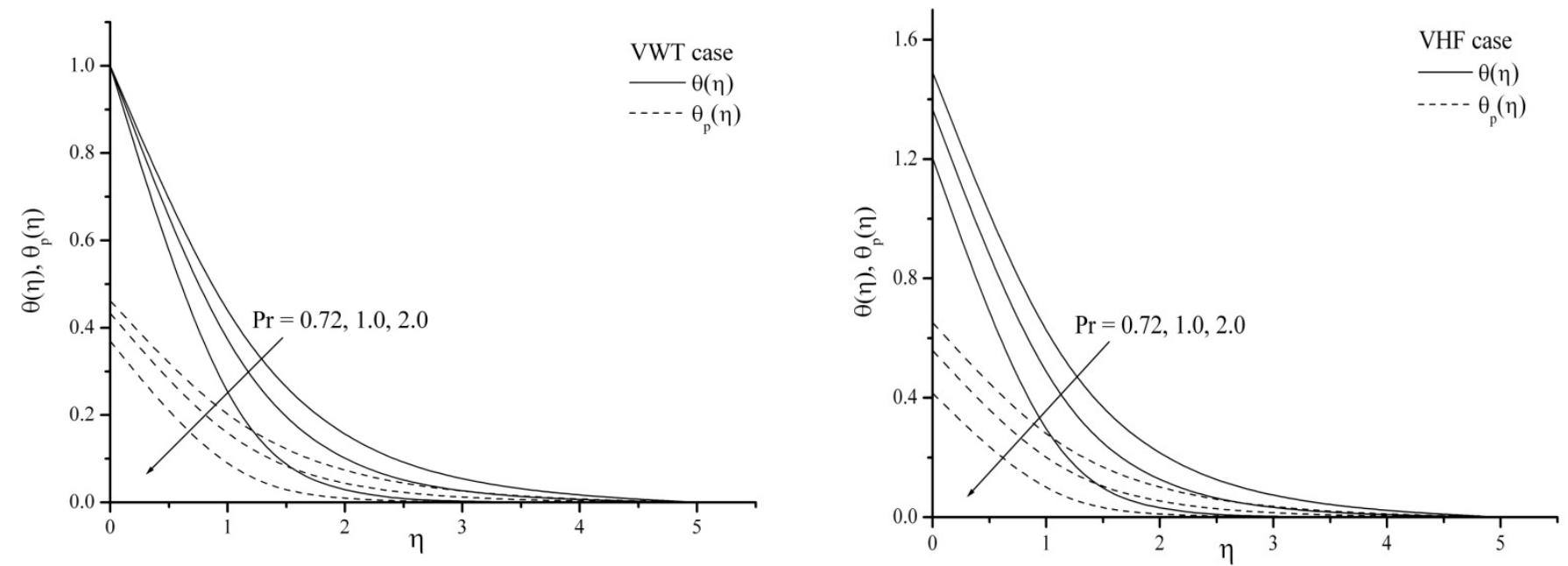

Figure 4(a) \& 4(b): Effect of Prandtl number Pr on temperature distribution for fluid and dust phase. 

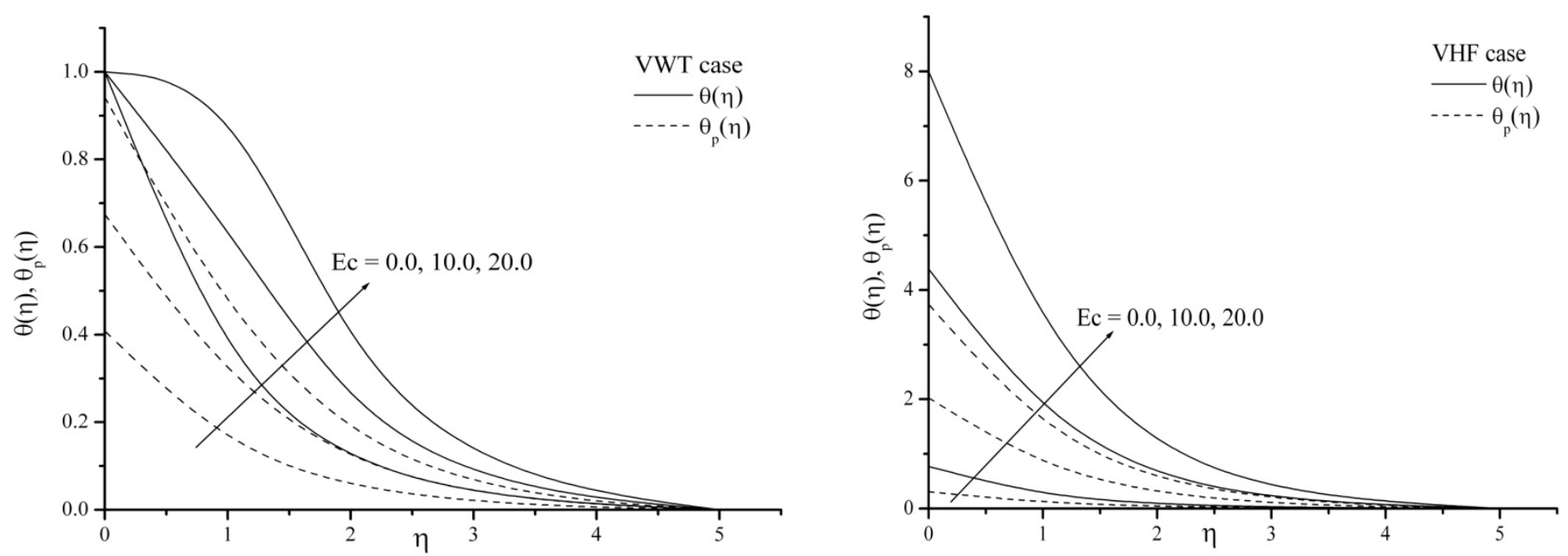

Figure 5(a) \& 5(b): Effect of Eckert number Ec on temperature distribution for fluid and dust phase.
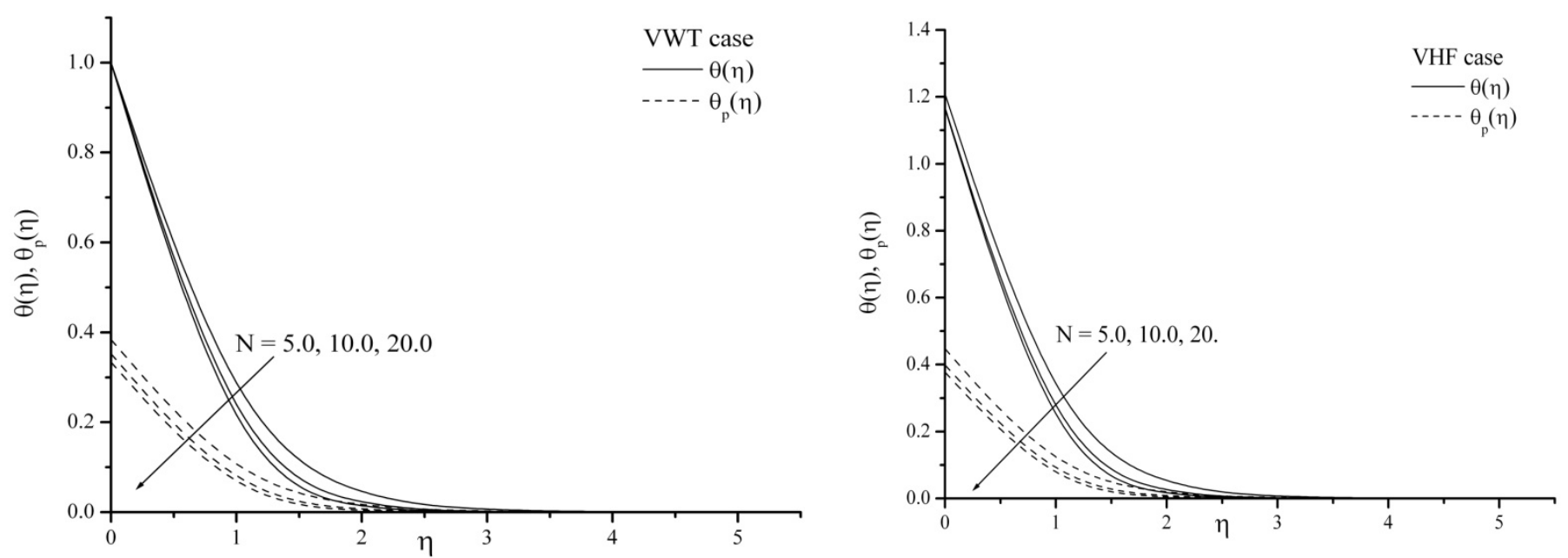

Figure 6(a) \& 6(b): Effect of Number density $N$ on temperature distribution for fluid and dust phase.
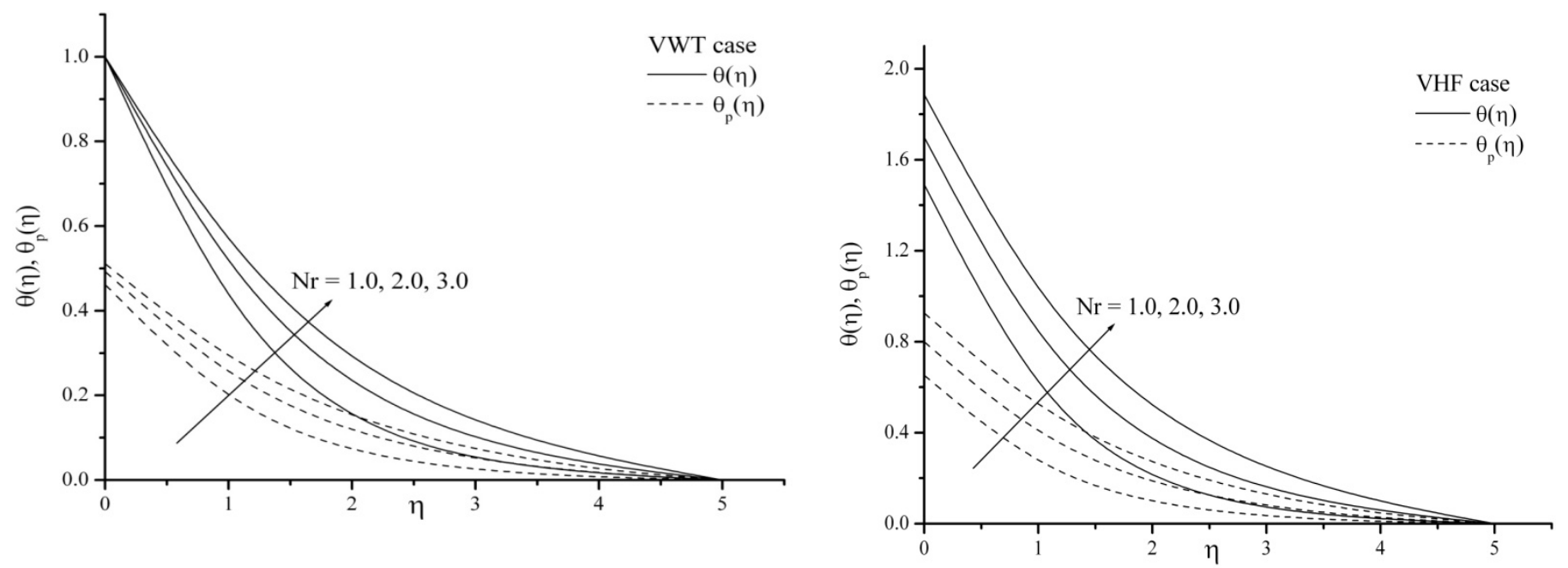

Figure 7(a) \& 7(b): Effect of thermal radiation parameter $N r$ on temperature distribution for fluid and dust phase. 
Table -3: Values of wall temperature gradient $\theta^{\prime}(0)$ (for VWT Case) and wall temperature function $\theta(0)$ (for VHF Case).

\begin{tabular}{|c|c|c|c|c|c|c|c|}
\hline$\beta$ & $A$ & $\operatorname{Pr}$ & $E c$ & $N r$ & $N$ & $\begin{array}{c}\theta^{\prime}(0) \\
(\mathrm{VWT})\end{array}$ & $\begin{array}{c}\theta(0) \\
(\mathrm{VHF})\end{array}$ \\
\hline 0.1 & 0.5 & 0.72 & 1 & 1 & 0.2 & -0.459164 & 0.842381 \\
\hline 0.5 & & & & & & -0.467992 & 0.840474 \\
\hline 1.0 & & & & & & -0.468768 & 0.840457 \\
\hline \multirow[t]{3}{*}{0.1} & 0 & .072 & 1 & 1 & 0.2 & -0.184235 & 0.996663 \\
\hline & 0.3 & & & & & -0.361637 & 0.891859 \\
\hline & 0.5 & & & & & -0.467992 & 0.840457 \\
\hline \multirow[t]{3}{*}{0.1} & 0.5 & 0.72 & 1 & 1 & 0.2 & -0.384693 & 0.840457 \\
\hline & & 1.0 & & & & -0.417967 & 0.673303 \\
\hline & & 20. & & & & -0.467992 & 0.429023 \\
\hline \multirow[t]{3}{*}{0.1} & 0.5 & 0.72 & 0.0 & 1 & 0.2 & -0.401060 & 0.768175 \\
\hline & & & 0.5 & & & -0.360831 & 0.948880 \\
\hline & & & 2.0 & & & -0.251751 & 1.490993 \\
\hline \multirow[t]{3}{*}{0.1} & 0.5 & 0.72 & 1 & 1 & 0.2 & -0.387125 & 0.906330 \\
\hline & & & & 2 & & -0.451612 & 0.805108 \\
\hline & & & & 3 & & -0.507068 & 0.714092 \\
\hline \multirow[t]{3}{*}{0.1} & 0.5 & 0.72 & 1 & 1 & 0.5 & -0.360831 & 0.948880 \\
\hline & & & & & 1.5 & -0.327409 & 1.203803 \\
\hline & & & & & 3.0 & -0.304771 & 1.427254 \\
\hline
\end{tabular}




\section{Conclusions}

In this paper, a mathematical analysis has been carried out on momentum and heat transfer characteristics in an incompressible viscous unsteady dusty fluid flow over a stretching sheet in the presence of thermal radiation. The highly non-linear momentum equations (2.1) to (2.5) and heat transfer boundary layer equations (3.1) and (3.2) are converted into coupled ordinary differential equations by using similarity transformations. Resultant coupled ordinary differential equations (2.8) to (2.11) and (3.9) and (3.10) for VWT case and (3.13) and (3.14) for VHF case have been solved numerically by RKF45 method using the software Maple (2009). The results are analyzed for the situation when stretching boundary is prescribed by non-isothermal variable wall temperature (VWT) which varies quadratically with the flow directional coordinate $X$. The effect of various physical parameters like unsteady parameter $A$, Prandtl number $\operatorname{Pr}$, Eckret number $E c$, Magnetic parameter $M$, number density $N$ and thermal radiation parameter $\mathrm{Nr}$ on various momentum and heat transfer characteristics are obtained. Some of the important observations are listed as follows

- The effect of unsteady parameter and Magnetic parameter decreases the fluid and dust phase velocities.

- Effect of unsteady parameter decreases the temperature profiles of fluid and dust

- phase for both the cases of VWT and VHF.

- Prandtl number effect decreases the thermal boundary layer thickness.

- $\theta^{\prime}(0)$ and $\theta(0)$ decreases with increase in the fluid interaction parameter $\beta$, unsteady parameter $A$, Prandtl number Pr .

- $\theta^{\prime}(0)$ and $\theta(0)$ increases with increase in the values of radiation parameter and Eckert number.

- Thermal radiation parameter effect increases the temperature profile of fluid and dust phases for both the cases of VWT and VHF.

- The rate of heat transfer $\theta^{\prime}(0)$ is negative (VWT) and $\theta(0)$ is positive (VHF).

- If $A \rightarrow 0, \beta \rightarrow 0, N r \rightarrow 0$ and $N \rightarrow 0$, then our results coincides with the results of Abel et.al (2008) and Grubka et.al (1985) for different values Prandtl number.

\section{Nomenclature}

\begin{tabular}{|c|c|}
\hline$(u, v)$ & Velocity components of the fluid phases along $x$ and $y$ directions \\
\hline$\left(u_{p}, v_{p}\right)$ & Velocity components of the dust phases along $x$ and $y$ directions \\
\hline$\mu$ & Co-efficient of viscosity of the fluid \\
\hline$\rho$ & Density of the fluid \\
\hline$N$ & Number of dust particles \\
\hline$\hat{B}_{0}$ & Induced magnetic field \\
\hline$\rho_{p}$ & Density of particle phase \\
\hline$K$ & Stoke's constant \\
\hline$U_{w}(x)=\frac{c x}{1-\alpha t}$ & Velocity of sheet \\
\hline$V_{w}(x, t)=-\frac{V_{0}}{\sqrt{1-\alpha t}}$ & Suction velocity \\
\hline$\alpha$ & Positive constant which measures the unsteadiness \\
\hline$\rho_{r}=\rho_{p} / \rho$ & Relative density \\
\hline$A=\alpha / c$ & Unsteady parameter \\
\hline$l=m N / \rho_{p}$ & Mass concentration \\
\hline$M=\sigma B_{0}^{2} / \tau C$ & Magnetic field parameter \\
\hline
\end{tabular}




$\begin{array}{ll}\beta=\frac{1}{\tau c}(1-\alpha t) & \text { Fluid-particle interaction parameter } \\ R=\frac{v_{0}}{\sqrt{v C}} & \text { Suction parameter } \\ E & \text { Density ratio } \\ T & \text { Temperature of the fluid phase } \\ T_{p} & \text { Temperature of the dust particle phase } \\ c_{p} & \text { Specific heat of fluid } \\ c_{m} & \text { Specific heat of dust particles } \\ \tau_{T} & \text { Thermal equilibrium time } \\ \tau_{v} & \text { Relaxation time of the of dust particle } \\ k^{*} & \text { Thermal conductivity } \\ q_{r} & \text { Radiative heat flux } \\ T_{w} & \text { Surface temperature of the wall } \\ T_{\infty} & \text { Constant temperature far away from the sheet } \\ \operatorname{Pr}=\mu c_{p} / k^{*} & \text { Prandtl number } \\ E c=v^{2} / T_{\infty} c_{p} & \text { Eckert number } \\ N r=16 T_{\infty}^{3} \sigma^{*} / 3 k_{1} k^{*} & \text { Thermal radiative parameter } \\ a_{1}=1 / \rho \tau_{T} C^{2}(1-\alpha t) & \text { Local fluid-particle interaction parameters for temperature } \\ \sigma^{*} & \text { Stefan-Boltzman constant } \\ k_{1} & \text { Mean absorption coefficient. }\end{array}$

\section{Acknowledgement}

We express our thanks to the University Grant commission New Delhi, for financial support to pursue this work under a Major Research Project (F.No.36- 147/2008/(SR)/dated:26-03-2009 ).

\section{References}

Abdul Aziz, 2009. A similarity solution for laminar thermal boundary layer over a flat plate with a convective surface boundary condition, Communications in Nonlinear Science and Numerical Simulation, Vol. 14, pp. 1064-1068.

Anura Ishak, 2010. Thermal boundary layer flow over a stretching sheet in a micropolar fluid with radiation effect. Maccanica, Vol. 45, pp. 367-373.

Andersson, H. T., Aareseth, J. B. and Dandapat, B. S. 2000. Heat transfer in a liquid film on an unsteady stretching surface. International Journal of Heat and Mass Transfer. Vol. 43, pp. 69-74.

Ali, F. M., Nazar, R., Arifin, N. M. and Pop, I. 2011. Unsteady flow and heat transfer past an ax symmetric permeable shrinking sheet with radiation effect. International Journal for Numerical Methods in Fluids. Vol. 67, No. 10, pp. 1310-1320.

Brewster, M.Q. 1972. Thermal radiative transfer properties. John Wiley and Sons.

Carragher, P. and Crane, L. J. 1982. Heat transfer on a continuous stretching surface. Int. J. App. Math. Mech. (ZAMM), Vol. 62, pp.564-565.

Elbashbeshy, E.M.A. and Aldawody, D.A. 2010. Effect of thermal radiation and magnetic field on unsteady mixed convection flow and heat transfer over a porous stretching surface. International Journal of Nonlinear Sciences. Vol. 9, No. 4, pp. 448-454.

Grubka, L. J. and Bobba, K. M. 1985. Heat transfer characteristics of a continuous stretching surface with variable temperature. International Journal of Heat and Mass Transfer. Vol. 107, pp. 248-250. 
Hayat, T., Qasim, M. and Mesloub, S. 2011. MHD flow and heat transfer over permeable stretching sheet with slip conditions. International Journal for Numerical Methods in Fluids. Vol. 66, pp. 963-975.

Mukhopadhyay, S. 2009. Effect of thermal radiation on unsteady mixed convection flow and heat transfer over a porous stretching surface in porous medium. International Journal of Heat and Mass Transfer, Vol. 52, pp. 3261-3265.

Sakiadis, B. C. 1961. Boundary layer behaviour on continuous solid surface; I Boundary-layer equations for two-dimensional and ax symmetric flow. Americal Institute of Chemical Engineers Journal, Vol.7, pp. 26-28.

Sharma, P. R. and Singh, G. 2009. Effects of Variable Thermal Conductivity and Heat Source /Sink on MHD Flow Near a Stagnation Point on a Linearly Stretching. Journal of Applied Fluid Mechanics. Vol. 02, pp. 13-21.

Subhas Abel , M., Mahesha, N. and Jagadish Tawade 2009. Heat transfer in a liquid film over an unsteady stretching surface with viscous dissipation in presence of external magnetic field. Applied Mathematical Modelling. Vol. 33, pp. 3430-3441.

Sharidan, S., Mahmood, T. and Pop, I. 2006. Similarity solutions for the unsteady boundary layer flow and heat transfer due to a stretching sheet. International Journal of Applied Mechanics and Engineering. Vol. 11, No. 3, pp. 647-654.

Subhas Abel, M., Siddeshwar P.G. and Mahantesh M. Nandeppanavar. 2007. Heat transfer in a viscoelastic boundary layer flow over a stretching sheet with viscous dissipation and non-uniform heat source. International Journal of Heat and Mass Transfer. Vol. 50, pp. 960-966.

Saffman, P.G. 1962. On the stability of laminar flow of a dusty gas, Journal of Fluid Mechanics. Vol. 13, pp.120-128.

Subhas Abel, M. and Mahesha, N. 2008. Heat transfer in MHD viscoelastic fluid flow over a stretching sheet with variable thermal conductivity, non-uniform heat source and radiation. Applied Mathematical Modelling, Vol. 32, pp. 1965-1983.

Tasawar Hayat, Muhammad Qasim, and Zaheer Abbas. 2010. Radiation and mass transfer effects on the magnetohydrodynamic unsteady flow induced by a stretching sheet. Z. Naturforsch. Vol. 65, pp.231-239.

Tsou, F. K., Sparrow, E. M. and Glodstein, R. J. 1967. Flow and heat transfer in the boundary layer on a continuous moving surface. International Journal of Heat Mass Transfer, Vol.10, pp.219-235.

Vajravelu, K. and Nayfeh, J. 1992. Hydromagnetic flow of a dusty fluid over a stretching sheet. International Journal of Nonlinear Mechanics. Vol. 27, No. 6, pp. 937-945.

\section{Biographical notes}

S. Manjunatha is in the Department of Studies and Research in Mathematics, Kuvempu University, Shankaraghatta-577 451, Shimoga, Karnataka, INDIA.

Dr. B.J.Gireesha is an Assistant Professor in the Department of Studies and Research in Mathematics, Kuvempu University, Shankaraghatta-577 451, Shimoga, Karnataka, INDIA. He has more than 14 years of experience in teaching and research. His current area of research includes Fluid Mechanics, Differential Geometry and Computer simulation. He has published more than seventy five papers in referred national and international journals. He has also presented more than twenty five research articles in national and international conferences. He has authored and coauthored 3 books. He is currently dealing with two projects sponsored by Government of India. 4 students are awarded Ph.D., and 11 students are awarded M.Phil., degree under his supervision.

Dr. C.S.Bagewadi is a Professor in the Department of Studies and Research in Mathematics, Kuvempu University, Shankaraghatta-577 451, Shimoga, Karnataka, INDIA. He has more than 25 years of experience in teaching and research. He has worked as acting Vice Chancellor Kuvempu University, Dean, Faculty of Science and Technology, Director, School of Physical Sciences, Kuvempu University. He has visited the Universities of North Korea and University of Hongkong under UGC cultural exchange programme. His current area of research includes His research interests include the areas of Fluid Mechanics, Differential Geometry and Computer simulation. He has published more than 150 research papers in International/National journals and to his credit 19 students have got Ph.D., and 13 have got M.Phil degree. He has authored and coauthored 6 books, and editor of 2 conference proceedings. He has given a number of lectures in conferences held in India and abroad. His name is include in Asia "Who is Who". He has been awarded as Best Citizen-2007. He has organized number of International/National Conferences and Refresher courses sponsored by UGC, DST, NBHM, CSIR etc., He is member for several academic bodies and various National and International Journals.

Received June 2012

Accepted July 2012

Final acceptance in revised form December 2012 